\title{
PEMAHAMAN PEMBUATAN RPP YANG KREATIF DAN PENGAPLIKASIANNYA DALAM PEMBELAJARAN
}

\author{
Laesa Ayun, Alfa Alfi Rahmawati, Anisa Septi Purwaningsih \\ Universitas Kristen Satya Wacana Jawa Tengah, Indonesia \\ Email: student.uksw.edu
}

\begin{abstract}
INFO ARTIKEL ABSTRAK
Diterima Penelitian bertujuan untuk menganalisis pemahaman dan penyusunan

22 September 2021 Rencana Pelaksanaan Pembelajaran (RPP) dan pengaplikasian model

Direvisi pembelajaran K-13. Penelitian merupakan jenis kualitatif. Populasinya

6 Oktober 2021

Disetujui

10 Oktober 2021 penelitian yaitu semua di SDN 2 Bringin kecamatan Bringin. Sampel yang diambil adalah 6 orang guru dari sdn Bringin 2. Data penelitian diperoleh melalui kegiatan seminar yang dilakukan kepala sekolah SDN Bringin 2. Hasil penelitian menunjukan dari 6 guru terdapat 2 guru atau $35 \%$ guru

Kata Kunci:

Supervisi, Model

Kurikulum 2013,

Rencana

Pembelajaran. memahami pembuatan Rencana Pelaksanaan Pembelajaran (RPP) dan model pembelajaran K-13. Sedangkan 4 guru belum memahami pembuatan RPP yang kreatif untuk pembelajaran Hal ini dapat disimpulkan guru SDN Bringin 2 Kecamatan Bringin Belum memahami pembuatan Rencana Pelaksanaan Pembelajaran (RPP) dan model pembelajaran K-13. Dari itu semua perlu adanya penyuluhan dan koordinasi kepala sekolah kepada guru untuk dapat meningkatkan kreatifitas pembuatan RPP sehingga pembelajaran yang akan terlaksana bisa kreatif sesuai tujuan pendidikan yang akan dicapai.
\end{abstract}

\section{ABSTRACT}

The research aims to analyze the understanding and preparation of the Learning Implementation Plan (RPP) and the application of the $K-13$ learning model. Research is a qualitative type. The research population is all in SDN 2 Bringin, Bringin sub-district. The samples taken were 6 teachers from Bringin 2 Elementary School. The research data was obtained through seminar activities conducted by the Bringin 2 Elementary School principal. The results showed that from 6 teachers there were 2 teachers or $35 \%$ of teachers understood the making of Keyword: Learning Implementation Plans (RPP) and learning models. K-13. Supervision, 2013 Meanwhile, 4 teachers did not understand the making of creative lesson Curriculum Model, plans for learning. From that all there is a need for counseling and Learning Plan coordination of school principals to teachers to be able to increase creativity in making lesson plans so that learning that will be carried out can be creative according to the educational goals to be achieved..

\section{Pendahuluan}

Rencana Pelaksanaan Pembelajaran (RPP) merupakan suatu rencana kegiatan pembelajaran tatap muka untuk satu pertemuan atau lebih (Permendikbud Nomor 65 Tahun 2013 tentang Standar Proses).
Perkembangan pada era teknologi dan informasi yang menunjukan perkembangan tanpa batas. Pada zaman sekarang ini dituntut sumber daya manusia (SDM) berkualitas. Langkah awal dari itu semua adalah sumber daya manusia di bidang pendidikan. Suatu bangsa akan menjadi lebih baik jika sumber 
Laesa Ayun, Alfa Alfi Rahmawati, Anisa Septi Purwaningsih

daya dipendidikan terus diperbaiki. Pemerintah Indonesia melakukan upaya melalui kegiatan penyempurnaanpenyempurnaan kurikulum pendidikan (Supriadi, 2009).

Saat ini pemerintah telah melakukan peningkatan kurikulum dari KTSP menuju K13. K-13 ini berpatokan kepada peningkatan pada proses sikap, proses keterampilan dan perolehan pengetahuan. Harapan pemerintah bahwa lulusan tersebut tidak hanya sikap tapi juga pengetahuan, dan keterampilan (Depdiknas, 2003) (Utami et al., 2016)

Kurikulum 2013 menekankan pada dimensi pedagogik modern dalam pembelajaran, yaitu menggunakan pendekatan ilmiah. Pendekatan Ilmiah dalam kurikulum 2013 dikenal dengan nama scientific appoach dalam pembelajaran semua mata pelajaran meliputi kegiatan pengamatan (observing), bertanya (questioning) . berkelompok (associating), mencoba (experimenting), dan jaringan penghubung (networking) (Alimuddin, 2014).

Kurikulum 2013 memiliki tiga aspek penilaian, yaitu aspek pengetahuan, aspek keterampilan, dan aspek sikap dan perilaku. Pada materi pembelajaran kurikulum 2013 terdapat materi yang dirampingkan dan materi yang ditambahkan. Materi yang dirampingkan terlihat ada di materi Bahasa Indonesia, IPS, PPKn. Selanjutnya pada kurikulum 2013 materi yang ditambahkan adalah materi Matematika (Joseph, 2009).

Berdasarkan wawancara terdapat beberapa permasalahan mengenai pelaksanaan kurikulum 2013 di SDN Bringin 2. Salah satunya yaitu pemahaman guru terhadap pembuatan RPP. Untuk guru yang belum memahami pembuatan rpp dan pengaplikasian rpp maka akan diikut sertakan pada seminar seminar dan diberikan pengarahan yang lebih baik. Agar semua guru bisa memahami pembuatan rpp yang kreatif untuk perkembangan teknologi seperti saat ini.
Faktor penyebab guru kurang memahami penyusunan RPP adalah: 1) guru belum pernah mendapatkan bimbingan secara khusus bagaimana menyusun RPP yang baik dan benar dari kepala sekolah, 2) setiap guru mengajukan RPP untuk disyahkan oleh kepala sekolah tidak pernah disalahkan dan langsung ditanda tangani, 3) guru sangat jarang mengikuti Pendidikan dan pelatihan (Diklat) tentang penyusunan RPP yang baik dan benar, kalaupun ada yang pernah mengikuti kegiatannya kurang serius, di jadwalkan 5 (lima) hari kerja baru tiga hari sudah ditutup, 4) alasan klasik guru beralasan jumlah jam mengajarnya banyak sehingga tidak sempat untuk Menyusun RPP, prinsipnya yang penting mengajar di kelas dengan berpedoman dengan buku paket siswa yang sudah disediakan oleh pihak sekolah dan oleh peserta didik itu sendiri (Wikanengsih et al., 2015)

\section{Metode Penelitian}

Kegiatan ini bertujuan untuk meningkatkan pemahaman guru terhadap pelaksanaan K-13. Peneliti menggunakan kualitatif deskriptif yaitu mendapat data hasil dan menjelaskan fenomena yang terjadi dengan menggunakan bahasa sendiri (Anggito \& Setiawan, 2018)

Prosedur yang kami gunakan untuk mendapatkan data adalah dengan wawancara secara langsung kepada guru dan memberikan sebuah pertanyaan tentang Penyusunan RPP di SDN Bringin 02. Dengan wawancara kepala sekolah beserta guru kami mendapatkan hasil dan data untuk penelitian selanjutnya (Rachmawati, 2007). 
Instrumen pengumpulan data kami menggunakan rangkaian kegiatan untuk memperoleh data dan menjelaskan makna dari data tersebut. Penelitian ini dilakukan dengan tujuan untuk meningkatkan kreatifitas guru dalam pembuatan RPP dan meningkatkan pemahaman maupun pengaplikasian RPP dalam pembelajaran.Fokus peneliti terhadap Rencana RPP dengan model pembelajaran pada K-13 Revisi pada guru SDN Bringin 2 Kecamatan Bringin .

Dalam menganalisis data kami menggunakan metode kualitatif (Rijali, 2019), Saat melakukan penelitian, kita harus menganalisis data agar data yang didapat mudah dipahami. Analisis data juga penting untuk kita mendapatkan solusi atas permasalahan penelitian yang tengah dikerjakan.

\section{Hasil dan Pembahasan}

\section{A. Hasil Penelitian}

Wawancara dilaksanakan dengan menggunakan teknik purposive terhadap 6 orang narasumber kunci yang dilakukan di SD N Bringin 02, Kecamatan Bringin. Wawancara dengan Kepala Sekolah beserta guru kelas dilaksanakan pada hari Kamis, 9 September 2021. Wawancara kami lakukan secara langsung bersamasama. Berikut merupakan inisial guru beserta jabatannya.

Tabel 1

Inisial Guru Beserta Jabatan

\begin{tabular}{c|c}
\hline Nama Peserta & Jabatan \\
\hline NR & Guru Kelas 1 \\
ST & Guru Kelas 2 \\
KH & Guru Kelas 3 \\
PS & Guru Kelas 4 \\
RN & Guru Kelas 5 \\
DS & Guru Kelas 6 \\
\hline
\end{tabular}

Kepala sekolah mengarahkan guru dalam pembuatan RPP yang kreatif kemudian mengamati guru dalam mengaplikasikan RPP yang telah dibuat guru. Kegiatan diawali dengan menentukan kalender pendidikan, membuat promes, prota, RPP sampai penilaian afektif, psikomotor, kognitif. Prota atau promes dinilai berdasarkan alokasi waktu pada kalender pendidikan. Selanjutnya yang akan dinilai RPP berdasarkan Kompeten Dasar, materi pembelajaran, tujuan kegiatan pembelajaran, metode/teknik pembelajaran dan evaluasi pembelajaran.

Survey kepala sekolah di SDN 2 Bringin berfokus pada (1) pemahaman konsep pembuatan RPP sehingga anak berfikir kritis, inovatif dan aktif, (2) melakukan kegiatan pembimbingan menyusun silabus yang terfokus pada standar isi dan prinsip pengembangan kurikulum, (3) melakukan bimbingan penggunaan media pembelajaran sesuai RPP.

Tabel 2

\begin{tabular}{ccccc}
\multicolumn{5}{c}{ Penilaian Hasil Pembuatan RPP Guru } \\
\cline { 1 - 4 } $\begin{array}{c}\text { Nama } \\
\text { Guru }\end{array}$ & $\begin{array}{c}\text { Kompoeten } \\
\text { Dasar }\end{array}$ & $\begin{array}{c}\text { Materi } \\
\text { Pembelajaran }\end{array}$ & $\begin{array}{c}\text { Tujuan } \\
\text { Pembelajaran }\end{array}$ \\
\cline { 2 - 4 } NR & 4 & 4 & 3 & 92 \\
ST & 4 & 3 & 3 & 85 \\
KH & 4 & 4 & 4 & 100 \\
PS & 4 & 3 & 4 & 92 \\
RN & 4 & 4 & 4 & 100 \\
DS & 4 & 4 & 3 & 92 \\
\hline
\end{tabular}

Kepala sekolah telah melihat dan mensurvey guru kelas dalam pembuatan RPP dan pengaplikasiannya dalam pembelajaran yang dilaksanakan dalam kelas. Peningkatan guru telah terlihat dan bisa mendapatkan skor yang tinggi dengan presentase $87 \%$ guru telah memahami dan mengalami peningkatan dalam pembuatan RPP yang memunculkan berfikir kritis siswa. 
B. Pembahasan

Kurikulum 2013 memiliki tiga aspek penilaian, yaitu aspek pengetahuan, aspek keterampilan, dan aspek sikap dan perilaku. Pada materi pembelajaran kurikulum 2013 terdapat materi yang dirampingkan dan materi yang ditambahkan. Materi yang dirampingkan terlihat ada di materi Bahasa Indonesia, IPS, PPKn. Selanjutnya pada kurikulum 2013 materi yang ditambahkan adalah materi Matematika (Joseph, 2009)

Dalam penelitian yang kami lakukan ini untuk mengetahui seberapa baiknya pemahaman guru dalam pembuatan Rancangan Pelaksanaan Pembelajaran (RPP) yang kreatif dan inovatif. Sesuai dengan Kurikulum 2013 tentang pembelajaran Sekolah Dasar 2013 terdapat pada permendikbud Nomor 67. Aturan tersebut berisi: (a) proses spiritual dan sosial (b) pengalaman belajar siswa seharihari (c) afektif, kognitif, serta psikomotor (d) pengembangan karakter positif siswa (Kementrian Pendidikan dan Kebudayaan Republik Indonesia), 2013).

Dalam pengembangan pendidikan yang maju guru harus memahami dasar pembuatan RPP yang kreatif untuk pembelajaran yang menarik. Berdasarkan hasil penelitian diperoleh terdapat 3 kategori yang akan diamatati adalah RPP, Silabus, Praktek mengajaar. Terdapat 6 guru di SDN Bringin 02, Kecamatan Bringin yang telah mencapai nilai diatas 2 per indikator dengan kategori baik dengan persentase $87 \%$ dan terdapat 2 orang guru yang memiliki nilai indikator 2 dengan kategori cukup yaitu sebanyak $13 \%$ secara keseluruhan dengan rata-rata skor 83,3 kategori baik.

Dalam penelitian yang kami lakukan ini menggunakan metode kualitatif sehingga lebih efektif karena memperoleh data secara langsung ke lapangan. Dalam penelitian kami menemukan banyak sekali data dan informasi. Salah satunya RPP yang disusun guru ada yang belum sesuai dengan tujuan pendidikan.

Berdasarkan wawancara dengan kepala sekolah beserta Guru kelas terdapat masalah utama dan masalah pendamping terkait pelaksanaan K-13 di SDN 02 Bringin Kecamatan Bringin. Kepala SDN 02 Bringin ditemukan: pertama, pada sekolah tersebut terdapat 6 guru mulai dari guru kelas hingga guru bidang studi, terdapat 2 orang guru atau sekitar $43 \%$ guru tidak bisa menciptakan RPP sendiri dan $57 \%$ guru membuat RPP-nya sendiri. Hal ini sesuai dengan penelitian Mislinawati \& Nurmansyah (2018) bahwa $60 \%$ guru kesulitan membuat RPP sendiri (Mislinawati \& Nurmasyitah, 2018).

Maka dari penelitian ini kami mendapatkan solusi untuk guru di SD N 02 Bringin untuk mengikuti seminar, pelatihan , dan edukasi dari kepala sekolah tentang penyusunan RPP yang kreatif, inovatif, dan dapat membuat pembelajaran yang menarik bagi siswa. Dengan guru memahami penyusunan RPP yang baik sehingga siswa dapat memahami pembelajaran dan mampu membuat siswa kreatif serta berfikir kritis untuk pengetahuan siswa. Dalam pembuatan RPP juga harus mencangkup keaktifan siswa dalam pembelajaran sehingga siswa tidak hanya diam saja, tetapi bisa aktif dalam pembelajaran . Guru-guru harus diarahkan untuk menulis RPP dengan sangat rinci sehingga banyak menghabiskan waktu yang seharusnya bisa lebih difokuskan untuk mempersiapkan dan mengevaluasi proses pembelajaran itu sendiri.

Saat ini Kurikulum acuan Kurikulum acuan dalam mencapai tujuan pendidikan nasional di era teknologi dan informasi ini. Kurikulum disusun secara menyeluruh di seluruh negara termasuk Indonesia. Adanya kurikulum membuat kesetaraan antara dari segi kompetensi dan tujuan 
pembelajaran. Indonesia telah menjalani sepuluh kali perubahan kurikulum (Octova et al., 2014) (Permendikbud, 2013). dalam mencapai tujuan pendidikan nasional di era teknologi dan informasi ini. Kurikulum disusun secara menyeluruh di seluruh negara termasuk Indonesia. Adanya kurikulum membuat kesetaraan antara dari segi kompetensi dan tujuan pembelajaran. Indonesia telah menjalani sepuluh kali perubahan kurikulum (Octova et al., 2014) (Permendikbud, 2013). Sehingga seorang guru harus mampu mengembangkan dan menyusun RPP dengan profesional.

\section{Kesimpulan}

Berdasarkan pemaparan diatas maka diperolah kesimpulan bahwasanya guru yang awalnya belum memahami RPP setelah diberi arahan menjadi paham. Langkah-langkah RPP telah sesuai denganmodel yang digunakan pelaksanaan K-13 Revisi. Pembuatan RPP menggunakan kreatifitas untuk memunculkan pemikiran siswa yang kritis.

\section{Bibliografi}

Alimuddin, A. (2014). Penilaian dalam kurikulum 2013. Prosiding, 1(1), 2333.Google Scholar

Anggito, A., \& Setiawan, J. (2018). Metodologi penelitian kualitatif. CV Jejak (Jejak Publisher). Google Scholar

Joseph, W. (2009). Implementasi Kurikulum Tingkat Satuan Pendidikan (KTSP): Dalam Pembelajaran Seni Musik di SMA CitiSchool Semarang. Harmonia: Journal of Arts Research and Education, 9(1). Google Scholar

Mislinawati, M., \& Nurmasyitah, N. (2018). Kendala Guru Dalam Menerapkan Model-Model Pembelajaran Berdasarkan Kurikulum 2013 Pada SD NEGERI 62 Banda Aceh. Jurnal Pesona Dasar, 6(2). Google Scholar

Octova, A., Bentri, A., Putra, A., Hidayati, A.,
\& Rahmi, A. (2014). Implmenentasi Kurikulum 2013 di Sumatera Barat. Jurnal Penelitian Pendidikan, 5(1), 8899. Google Scholar

Rachmawati, I. N. (2007). Pengumpulan data dalam penelitian kualitatif: wawancara. Jurnal Keperawatan Indonesia, 11(1), 35-40. Google Scholar

Rijali, A. (2019). Analisis data kualitatif. Alhadharah: Jurnal Ilmu Dakwah, 17(33), 81-95. Google Scholar

Supriadi, O. (2009). Pengembangan profesionalisme guru sekolah dasar. Jurnal Tabularasa, 6(1), 27-38. Google Scholar

Utami, B., Yamtinah, S., \& ES, W. A. (2016). Analisis Rencana Pelaksanaan Pembelajaran Tematik yang Disusun Guru SD. Prosiding SNPS (Seminar Nasional Pendidikan Sains), 3, 361-366. Google Scholar

Wikanengsih, W., Nofiyanti, N., Ismayani, M., \& Permana, I. (2015). Analisis Rencana Pelaksanaan Pembelajaran (RPP) Mata Pelajaran Bahasa Indonesia (Studi terhadap RPP yang Disusun Guru Bahasa Indonesia Tingkat SMP di Kota Cimahi). Jurnal Ilmiah P2M STKIP Siliwangi, 2(1), 106-119. Google Scholar 

Laesa Ayun, Alfa Alfi Rahmawati, Anisa Septi Purwaningsih

\section{Copyright holder :}

Laesa Ayun, Alfa Alfi Rahmawati, Anisa Septi Purwaningsih (2021).

First publication right :

Action Research Literate

This article is licensed under:

(c) (i) (O) 